Advances in Intelligent Systems and Computing 974

Amic G. Ho Editor

Advances in Human

Factors in Communication

of Design

Proceedings of the AHFE 2019

International Conference on Human

Factors in Communication of Design,

July 24-28, 2019, Washington D.C.,

USA

Springer 
Amic G. Ho

Editor

\section{Advances in Human Factors in Communication of Design}

Proceedings of the AHFE 2019 International Conference on Human Factors in Communication of Design, July 24-28, 2019, Washington D.C., USA

Springer 
Editor

Amic G. Ho

School of Arts and Social Sciences,

Creative Arts

Open University of Hong Kong,

Jubilee College

Ho Man Tin, Kowloon, Hong Kong

ISSN 2194-5357

ISSN 2194-5365 (electronic)

Advances in Intelligent Systems and Computing

ISBN 978-3-030-20499-0

ISBN 978-3-030-20500-3 (eBook)

https://doi.org/10.1007/978-3-030-20500-3

(C) Springer Nature Switzerland AG 2020

This work is subject to copyright. All rights are reserved by the Publisher, whether the whole or part of the material is concerned, specifically the rights of translation, reprinting, reuse of illustrations, recitation, broadcasting, reproduction on microfilms or in any other physical way, and transmission or information storage and retrieval, electronic adaptation, computer software, or by similar or dissimilar methodology now known or hereafter developed.

The use of general descriptive names, registered names, trademarks, service marks, etc. in this publication does not imply, even in the absence of a specific statement, that such names are exempt from the relevant protective laws and regulations and therefore free for general use.

The publisher, the authors and the editors are safe to assume that the advice and information in this book are believed to be true and accurate at the date of publication. Neither the publisher nor the authors or the editors give a warranty, expressed or implied, with respect to the material contained herein or for any errors or omissions that may have been made. The publisher remains neutral with regard to jurisdictional claims in published maps and institutional affiliations.

This Springer imprint is published by the registered company Springer Nature Switzerland AG

The registered company address is: Gewerbestrasse 11, 6330 Cham, Switzerland 


\section{Contents}

Communication Design and Practices

Nudge Users to Healthier Decisions: A Design Approach to Encounter

Misinformation in Health Forums . . . . . . . . . . . . . . . 3

Mahdi Ebnali and Cyrus Kian

How Creative Mindset Operates with Respect to Creative

Performance: Pedagogical Factors that Ignite Creative Mindset

in Design Education . . . . . . . . . . . . . . . . . . . . . . . . . . . 13

Joungyun Choi

Exploration and Thinking on the Cultural Communication

of Guangdong Museum

Xiaobao Yu and Ting Wang

Bullet Points: Applying Emotional Symbols

in Information Management.

Amic G. Ho

Impact of Inspiration Sources on Designer's Idea

Generation Strategy .

Xinyu Yang and Jianxin Cheng

Design in Advertising and Media Communication

Emotions in Advertising: How Emotions Affect Creativity

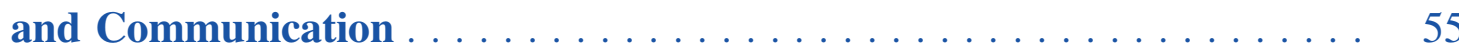

Amic G. Ho and Sunny Sui-kwong Lam

An Investigation into the Power of Digital Media in Hong Kong . . . . . 65

Edward C. K. Hung

Understanding How Advertising Gamification Influences Consumers:

The Effect of Image Experience and Interactivity . . . . . . . . . . . . 71

Yunbo Chen and Huijie Yao 
Locality and Local Identity Discourses in Post-handover Hong Kong

Brand Advertisements . . . . . . . . . . . . . . . . . . . . .

Sunny Sui-kwong Lam and Terry Lai-sim Ng

Mainstreaming Culture Jamming? Revisiting the Socio-Cultural

Impact of Viral Campaign . . . . . . . . . . . . . . . . . . . . . . . 95

Chi-kit Chan and Anna Wai-yee Yuen

Digital Generation's Meaning-Making in Web-Based

Communication Activities . . . . . . . . . . . . . . . . . . . . . . . . 106

Pui Wa Chau

Creative Arts

Improvement of Safety Sign Design Based on Analysis

Comprehensibility Test Result

Chuan-yu Zou and Yongquan Chen

Research on Design Communication Mode Based on White

Bi Theory . . . . . . . . . . . . . . . . . . . . . . . . . . . . . . . . . . . . . . . 124

Xinying Wu, Minggang Yang, and Xinxin Zhang

3D Scanning and Visual Dimension - Technological and Creative

Evolution

Man Lai-man Tin

Communication in Design

Kids at Preschool. Designing Products and Wayfinding Systems

to Enhance Kids' Skills, Facilitating Wellbeing

Through Communication . . . . . . . . . . . . . . . . . . . . . . . . 141

Laura Giraldi, Elisabetta Benelli, Marta Maini, and Francesca Morelli

Viral Marketing in Political Communication: Case Study of John

Tsang's Campaign in the 2017 Hong Kong Chief Executive Election . . . 151

Daren Chun-kit Poon and Sunny Sui-kwong Lam

Study on How Television Commercials Affect Consumer Reactions

with Visual Strategies . . . . . . . . . . . . . . . . . . . . . . . . . . . . . . 162

Pikki Fung and Amic G. Ho

A Comparative Study on the Language Expressions of Cultural and Creative Products in the East and West . . . . . . . . . . . . . . . . . 174

Chen Cheng, Junnan Ye, Hui Gao, and Guixiang Wu

The Advertising Effects of Typotecture: Associated Learning Factors and Emotions . . . . . . . . . . . . . . . . . . . . . . . . . . . . . . . . . . 182

Man-Yee Mak and Amic G. Ho 


\title{
Kids at Preschool. Designing Products and Wayfinding Systems to Enhance Kids' Skills, Facilitating Wellbeing Through Communication
}

\author{
Laura Giraldi $^{(\bowtie)}$, Elisabetta Benelli, Marta Maini, \\ and Francesca Morelli \\ University of Florence, Florence, Italy \\ \{laura.giraldi, elisabetta.benelli\}@unifi.it, \\ marta.maini@hotmail.it,francesca_morelli_@libero.it
}

\begin{abstract}
In our society kids spend a significant part of their life outside home up to eight hours a day there. In this environment, to feel safe kids "need" both rules to respect and freedom to live experiences. Still today pre-school are designed mainly according only to the ergonomics rules without considering emotional aspects. The main objective of this research is to identify a set of good practices to design pre-school products, furniture, interior settings and wayfinding systems able to enhance quality experiences on education and growing to integrate learning and teaching methods in pleasant experiences, improving awareness among the users. This paper aims to underline the importance of the communicative aspects of design for a new education approach based on "learning by doing".
\end{abstract}

Keywords: Children - Pre-school design - Kindergarten - Environment · Learning by doing $\cdot$ Communication $\cdot$ Emotion $\cdot$ Education

\section{Introduction}

\subsection{Context of Reference}

Nowadays, the educational tendencies in use refer, mostly, to educational models introduced in the past, based on principles such as relationship, experience, autonomy and security. Among the most widespread we underline the model of Maria Montessori based on independence and autonomy.

According to her theories, the educator's role is not to teach or judge children, but to help them, to be responsible and autonomous guiding them in a place that it is not competitive but collective. She used to say: "let's help them to do it alone" [1].

Really, the educational model does not only concern teaching, but it also refers to the surrounding space: "The environment must be welcoming [...] without superfluous things [...]. The furnishings must be child-friendly and all the spaces pleasant and welcoming [...]. The environment must be flexible for different work's activities and at the same time children have to adapt it by preparing it for their future work" [1]. 
The Loris Malaguzzi model, also known as Reggio Emilia Approach, is another very rife educational model. In addition to the previous educational model, he takes care of their moods, preferring the relationships and the interactions among children and their natural behaviors during workshop and multimedia activities.

He affirmed that "The child is made of a hundred languages, a hundred hands, a hundred thoughts, a hundred ways of thinking, of playing and speaking, a hundred ways of listening, $[\ldots]$ a hundred worlds to discover, a hundred worlds to invent, a hundred worlds to dream" [2].

The way to express children's emotions is through the activities carried out in the ateliers, spaces dedicated to artistic activities, where the expressive and poetic languages generate the necessary knowledge for the development of the child.

According to these models, the daytime in the kindergarten is divided into routines, dedicated to different tasks. The corresponding spaces must be designed in a way to guarantee all users' needs and facilitating the correct carrying out of all the activities.

Scanning the day in routines means teaching the child the behavioral rules that will accompany him throughout their present and future life.

\subsection{Interior Settings and Functions at Preschool}

Still today preschool is generally set in a traditional way as it was twenty or thirty years ago. Spaces and products are designed according to ergonomics rules, including measurements, furnishing, materials and surface finishes for safety [3].

Instead, it is also necessary to consider children taking into consideration their emotions. Despite the growing interest for this issue, which encompasses different disciplines (i.e. design, pedagogy, psychology) and despite the several international prizes on designing new buildings for pre-school, nowadays it is very difficult to find interiors specifically designed for them.

Generally the elements of pre-school interiors (furnishing, way-finding systems, graphics) are designed according to security requirements and anthropometric measures.

Regarding the distribution of spaces and functions for a long time the preschool was conceived as a unique place, developed in classrooms, while the other spaces had not importance because they were considered as subordinate to the centrality of the classroom. Today pedagogical studies on educational environment have proved the positive impact of spaces, products and furniture on kids' behaviour.

Different rooms and activities areas are furnished and equipped to foster discovery, exploration, social relation and interaction while promoting language, skills, creativity and the ability of problem solving.

Therefore, all the spaces should be organized to respond children's needs, they should be well characterized, differentiated and readable, and also safe and stimulating places to create a path of familiarization and knowledge that helps children to orientate spending pleasant time inside the kindergarten. The kindergarten is generally located in a building that welcomes children dispensing a variable range of services.

Preschool spaces are generally divided in the following main functional areas:

1. The entrance/welcome area

2. The classroom 
3. The playground

4. The sleeping/nap room

5. The refectory

6. Daycare bathrooms

7. Connective areas (corridors, stairs, halls)

8. The courtyard

Furthermore, sometimes there are also gym areas and common spaces dedicated to events and end of year performances. According to children's age there are different kind of furniture that is adapted respect to the specific measures and sometimes to the skills of the children.

The research focuses on the welcome area and the classroom, a flexible space were children live and experiment structured and free activities.

Welcome Area. The welcome area is a space, generally located close to the entrance of the school, representing the meeting point of educators, parents and children. This area has two main functions: the practical one contains kids' personal belongings such as clothes, shoes, toys; the second one, more important, facilitates the separation of children from parents and from their familiar environment. Consequently this area hosts daily rituals that develop the autonomy of children and welcome moments of school-family communication.

Classroom. The classroom is the main environment of the kindergarten where structured, semi-structured and free activities take place, including spaces for playing and for laboratories. During the activities children learn how to relate to the other children, socialize and live their first experiences developing skills towards their autonomy. It is important they have every activity carried out without judgment, in order to stimulate personal initiative. During structured activities children usually sit in common tables of 4/6 places, which are often adjusted ad hoc for individual or group work.

Playground. This area is often included in the classroom area but sometime some kindergarten has also a dedicated space. The playing activity is an expression of child's creativity that learns and refines his skills through experience. During this activity the child is completely free to move, to express oneself and to relate with those who prefer, while the teacher has the task of observer and can only be involved upon the child's invitation.

The environment, the furnishing, the everyday objects, the graphics and all the settings elements became strategic to design a pleasant and educational environment for children and educator.

\subsection{Children and Parents' Stress for Attending Preschool}

The start attending pre-school often causes stress and worries in children and parents since it represents a determining step for the correct psychophysical child development. The hardest transition for children is the necessary shift from being at home to entering the classroom while parents are worried for the unpleasant emotion of their children in separating from them and their habits. Moreover they are also stressed to entrust their children to extraneous educators in an unknown environment. Educators can, however, 
help children avoid the emotional stress, they feel during this time, by adding some welcome activities to their routines. Stress is a concept scientifically defined and an evincible phenomenon [4].

In 1998, Evans and Mitchell McCoy described the way a built environment may influence not only the health of persons but also behavior and found which architectonic elements may lead relevant stress in the users. In pre-school environment, the stress did not allow children to feel at ease influencing their behavior and comfort. According to Ulrich, Devlin, Arneill and Del Nord, the elements of the environment that may represent possible stress vehicle for users are the following: the image itself of the spaces, sensorial feelings, difficulties, impossibility in control and manipulate the environment, orientation difficulties, physical discomfort.

\section{The Aim of the Research}

The aim of the present research is to propose an innovative approach to the pre-school design. The research proposes a series of good practices to design pre-school products, furniture, interior settings and wayfinding systems able to enhance kids' quality experiences on education and growing. This study proposes a new collaborative and innovative approach in designing for preschool spaces to integrate learning and teaching methods in pleasant experiences, improving awareness among the users helping, at the same time, educators during daily routines.

Moreover the purpose of this work is to underline the strategic role of design, and in particular its communicative aspects able to transfer material qualities and intangible values suggesting behaviors, relations and interactions among persons and between persons and products. In order to improve the wellness of kids and make them feel at ease in pre-school spaces, it is necessary to render those ones more friendly and familiar.

The study aims, indeed, to guide designers to design interiors, furnishings, products and way-finding systems able to orient, inform, interact, entertain include all kind of children using a universal language coming from their collective imaginary. To improve this kind of design culture, the present study recommends a methodological referring system to be easy applied in different indoor places dedicated to children. The suggested good practices are designed taking into account the peculiarities (skills, emotions, behaviors) of children at different ages in accordance to the theory of Maria Montessori [5].

The main goal of this work is to propose a referring methodological system to design products for kids in kindergarten environment able to communicate with them according to two different levels:

1. The first communication level is designed to orientate children guiding them along interiors and making them familiar. As a consequence children feel themselves at ease. This kind of communication is usually based on children behavior and corresponding emotions so that they recognize both pleasant situations and furniture and object to be used for a particular tasks.

2. The second communication level, stimulating children to interact with the objects and the environment and to relate to other children, allow them to live conscious 
and educative experiences. These kind of communication is based on learning by doing through interactive and relational experiences children develop new skills and behaviors.

Summarizing the final research's aim is to find open rules and good practices for the design of kindergarten environment, flexible adjustable interactive, able to look familiar and to orient children stimulating pleasant and didactic experiences.

\section{Methods of Research}

\subsection{Methodological and Multidisciplinary Approach}

The research refers to the Human Factor approach in which children represent the key actors. To study children as main users, the design research used a multidisciplinary approach involving many actors from different disciplines as educators, psycho-logists, pedagogists, and even involving parents and children. The research starts from the studies of two Italian pedagogists Maria Montessori and Loris Malaguzzi, whose theories are the most followed all over the world. At the same time the present work uses the co-design method involving children in co-working to focalize on project priorities related to their unexpressed needs and emotions. Furthermore the work refers also to the education method based on "learning by doing", due to the practical approach centered on the material involvement of children in the environment and it works as a continuous training.

According to the Italian National Guide Line [6], pre-school educators should choose and propose children's activities to develop their specific skills. The present tools at their disposal today do not facilitate these tasks. Consequently, the design of kindergarten's environment (such as furniture, wayfinding systems, communication and products of daily use) plays a very important role in education, as the real responsible of the pre-school quality together with the educators. Starting from the consideration that children (3-6 years), according to their level of psycho-physical development, have their own skills and behaviors, it is necessary not only to study their needs before designing for them but also to outline a set of open rules for designer to take into account when designing for children.

By following the educational approaches we consider their indications about the environment of children life as a fundamental rules able to influence their development and growing [7]. Consequently, the design of children's pre-school environment (dealing with furniture, objects, graphic and interiors' element) needy to define a set of "basic elements" as, for instance, colors, graphics, shapes, helping designer to design according to children material and emotional needs.

Referring to children as main user it is important to use languages that they can easily understand and recognize, in designing for them. This is possible if we refer to kids' collective imaginary, necessary for capturing their interest and stimulating their skills. The research used also a co-design approach that has been experimented as described below during the development of the present work.

In particular, the research used the co-working activities for involving small users during design process. 


\subsection{Design Thinking and Co-working with Children}

The focus of the co-designing process is not only working together in order to product output, but also to enhancing the design skills of the participants. It is very important for the designer to know the users and particularly their material and emotional needs, habits, behaviors and all the practices of their daily routine. The main users of this research are the children. In our society adults make all the decisions for them, do not very often thinking at their real needs. The child so becomes just a passive actor of the society [8]. Moreover, sometimes children are treated like little adult, not considering their physical and emotional needs, while it is important to provide them the best way to communicate and to encourage creativity making them feel at ease, also during the workshop. Infact the co-working activity, as a practice of Design Thinking, is a creative way to communicate with children understanding their "needs" and desires.

In recent years children are more and more included in different phases of the design processes in various ways. Allison Druin in 2002 said that a child could have four different roles during the design process: it can be a user, a tester, an informant or a design partner [9]. Smith and Dindler have introduced on Druin's model the role of the "protagonist" that empowers the child more [10], as theorized also by the Reggio Emilia approach to early childhood education. Fenne Van Doorn expanded the role of the child in a design process, by introducing the role of co-researcher [11]. In this case the child is both the researcher and the user. During the co-working activity with children some important factors should be ta-ken into consideration: the children age, the environment and the activity.

Given that abilities and skills of children change according to their different age [12], it's necessary take this factor into consideration since it's fundamental for the choice of the activity to be adopted during the co-working.

The environment in which the co-working is carried out is the second factor to take into consideration. For this reason, the choice of well-known places such as schools may be reasonable.

The third factor, which is strictly connected to the other ones, is the activity. As theorized by Druin, the use of low-tech methods is a good practice to encourage the child to communicate with them. Paper, clay, Lego, crayons can be considered as examples of low-tech methods. It is important do not frighten and do not judge the child but make him feel at ease. In this way, the child can feel free to express himself. The co-working activity should be ludic and, in the same time, should make the child responsible for the project.

For the purpose of this research, two different co-designing examples have been carried out, involving children of different ages and in similar environments. In both cases, were executed elementary activities characterized by the use of paper, crayons, marking pens, stickers and stationery.

\section{Applied Method}

The research studied the following aspects, by relating them with the specific scenarios of the Italian pre-school: 
1. Study of the literature: perception psychology, children skills and behavior at the age of 3-6, way-finding systems, design for children, communication design, human factor design.

2. Direct observation of children at pre-school - as explained in the use case below.

3. Interviews to educators, and parents for detecting problems of welcoming, activities and orientation both for them and for children in pre-school.

4. Co-working activity with children aged 3 to 6 years.

5. Collection and comparison of results.

This practical activity of direct observation of children was based on the detection of their mood and needs when arriving at preschool, during daily routine, experimenting educational activities and playing.

The purpose of the co-working activity is also to know if and how children feel at ease and if they have difficult to orientate at preschool. Moreover, the experimentation aim to identify possible real solutions to designing furniture and products at preschool interpreting children suggestions and at the same time helping educators during their work with children.

The results have to find and/or verify a set of good practices to design preschool products and environment that are "children centered", using colors, shapes and familiar elements according to their own language and collective imaginary.

\subsection{Use Case: Co-working Design}

The experiment was set-up in Pontedera and Ponsacco, two small Italian towns close to Florence and involved eight pre-schools of mixed classes (aged 3-6) for a total amount of eight sections (one for each school) and 166 little students. The research has implemented three main actions that allowed to understanding better children behaviors:

1. Direct observation at welcome time and direct observation in classroom during different activities.

2. Interviews to educators.

3. Co-working activity with children.

These following actions were carried out within three months from September to December 2017.

Direct Observation. The observation started considering separately the entrance/ welcome area and the classroom. The activity has involved children aged from three to six years old. The observation showed how all the children were interacting with the environment and interior settings and how they were moving in the surrounding environment with and without their parents. The method's application points out, for the most, the difficulties of all the children to be oriented and feel comfortable in September during the beginning of the scholastic year. The observation also underlined that differently aged children common activity is the playing. Besides, the observation showed how children used to play with well-known and familiar elements, even if they were not designed specifically for playing. 
Interviews to Educators. For the research purposes, questionnaire and interviews related to the functional areas mostly experienced by children were conducted with the educators. Fifty educators from eight kindergartens have been involved. The eight pages length interview covered the aspects related to shapes, materials, dimensions, dispositions and functions of the products and the furniture. Further, also tried to question possible improvements of welcome area, the classrooms and the playground. Educators reacted positively to this initiative, pointing out the problems related to the kindergarten and offering solutions for the design of the environment. They highlighted that the present furniture is often dated, not easily usable, even not able to stimulate and increase the physical and mental development of children. Moreover, the need of a better interaction between children and pre-school environment was particularly underlined.

Co-working with Children. The co-working activity with children was carried out in sessions of an hour each. During the co-working the children, followed by designers and educators, were asked to draw their ideal furniture for the school and that could "make them feel at ease", using the materials they preferred. The co-working activities have underlined useful aspects and the main characteristics regarding to shapes and colors to be used later in project. The work with children allowed the researchers to understand their thoughts and emotions related to the preschool environment, and their needs related to the furniture. The co-working activities underline that children were mainly attracted by colorful furniture, simple and rounded shapes able to stimulate their creativity and make them feel at ease. During the sessions children have highlighted the material use importance of products in pre-school environment, drawing, for instance, furniture made by soft and pleasant touch material. Besides, they have drawn equipped and technological furniture, able to transform themselves, to be multifunction and adaptable to the needs.

\section{Results of the Research}

The research states that all the elements inside a preschool environment as, furniture, objects, graphics, communicates material meaning and immaterial values, for this reason they have to be designed by specific characteristics to absolve explicit purposes. These characteristics have to come from children's imaginary, because they need to learn through friendly objects and playful elements, during ritual activities of their daily routine.

As a result, the research proposes a series of good practices applicable to all kind of kindergarten environment, both for new and for existing ones. The following points summarize the proposed actions useful to design this kind of places at "children size".

The research underlines the need to set specific goals to material elements at kids' disposal according to educators (and parents) requests and to children personality and feels. The starting point is to associate a series of values to each "functional" environment at preschool.

The results propose two main sphere of referring for kindergarten environment:

1. Reassuring environment

2. Educational environment 
Each of the above design environments have to contain a series of specific elements necessary to obtain the prefixed goals.

Peculiarities of reassuring environment:

1. Protective: the child feels at ease in a safe environment through comforting and protective elements. Design elements' peculiarity: comfortable, cosy, pacify, realized by light colors, rounded shapes, small dimensions and soft touch materials.

2. Recognizable: the child is able to move in security and freedom orienting himself in spaces through ritual activities, familiar and customized elements. Design elements' peculiarity: ritual, familiar, from their imaginary, customized, realized by simple shapes, primary colors, easy to identify among others.

Peculiarities of Educational environment:

1. Interactive: the child is invited to interact with ludic aspects and with the elements' transformability. Design elements' peculiarity: visual, sound and light feedback. Use of simple and friendly shapes, soft materials, touching finishing, bright colors, intuitive graphic, multimedia elements.

2. Relational: the child is embroiled by functions, objects' shapes and their multifunctionality, especially if they work correctly with more than one user, stimulating and increasing collaboration, inclusion and relation-ship. Design elements' peculiarity: multifunctional shapes suggesting collaborative actions, simple info-graphics.

3. Experiencing: the child is involved by the environment, the furniture, the objects and all the material elements able to communicate information and inviting to the exploration. The living experience stimulates the sense for pleasant emotions or/and pass knowledge improving skills and abilities. Design elements' peculiarity: multifunction, transformable, friendly, enlightened, bright colors, unexpected graphic, smart materials, different kind of finishing, multimedia elements.

In conclusion the research suggests that all the elements of the kindergarten environment, must be both reassuring and educational in order to design a space "children centered" able to involve them in emotional and didactic experiences. In this way the experience at preschool becomes a pleasant training for the future life.

\section{Conclusions}

The results of the present work underline the importance for children to live in environment designed around their real attitudes, emotion and abilities. This work has identified a set of good practices and open rules to design pre-school environment, furniture, products and graphics according to children and educators "needs" with the final aim to improve children educational experience based on learning by doing.

Besides, the research highlights that all the material and graphic elements of children environment determine their living experience. The more these elements result familiar and reassuring, the more the experience will be pleasant influencing their security and wellness and as a consequence facilitating the educational experiences and development of their skills. 
In summary the results of the research points out that reassuring elements and experiential ones have a decisive influence on the life's quality inside the kindergarten. Children need familiar environment and everyday object, in order to feel at ease living educative experiences in freedom.

For the future we hope to share the result of the research in order to apply and to develop the proposed open rules for designing not only preschool but suggesting a new design approach "children-centered".

\section{References}

1. Montessori, M.: Educazione per un mondo nuovo. Garzanti, Milano (1970)

2. Filippini, T., Vecchi, V., Malaguzzi, L.: The Hundred Languages of Children. Reggio Children Editore, Reggio Emilia (1996-2005)

3. Wise, B.K., Wise, J.A.: Children's human factors in the design of a pre-school educational furnishings system. In: Human Factors and Ergonomics Society Annual Meeting Proceedings, vol. 35 , no. 8 , pp. 541-545 (1991)

4. Cox, T., Griffiths, A., Rial-Gonzalez, E.: Work-related stress. Office for Official Publications of the European Communities, Luxembourg (2000)

5. Montessori, M.: Dall'infanzia all'adolescenza. Garzanti, Milano (1949)

6. Ministero dell'istruzione dell'Università e della Ricerca. Indicazioni nazionali per il curricolo della scuola dell'infanzia e del primo ciclo di istruzione, Italia (2012)

7. Edwards, C.P., Gandini, L., Forman, G.E.: The Hundred Languages of Children: The Reggio Emilia Approach to Early Childhood Education. Ablex Publishing Corporation, Norwood (1993)

8. Clark, A.: Ways of seeing: using the Mosaic approach to listen to young children's perspectives. In: Clark, A., Kjørholt, A.T., Moss, P. (eds.) Beyond Listening, pp. 12-28 (2005)

9. Druin, A.: The role of children in the design of new technology. Behav. Inf. Technol. 21, $1-25$ (2002)

10. Iversen, O.S., Smith, R.C., Dindler, C.: Child as protagonist: expanding the role of children in participatory design. In: Proceedings of the 2017 Conference on Interaction Design and Children, Stanford, California (2017)

11. Van Doorn, F., Stappers, P.J., Gielen, M.: Children as coresearchers: more than just a roleplay. In: IDC 2014 (2014)

12. Piaget, J.: Lo sviluppo mentale del bambino e altri studi di psicologia. Einaudi, Torino (1967) 
In relazione al paper

Laura Giraldi, Elisabetta Benelli, Marta Mini, Francesca Morelli (2019). Kids at Preschool. Designing Products and Wayfinding Systems to Enhance Kids' Skills, Facilitating Wellbeing Through Communication. In: (a cora di): Amic G. Ho, Advances in Human Factors in Communication of Design. Proceedings of the AHFE 2019 International Conference on Human Factors in Communication of Design, vol. 974, p. 141-150, Springer Nature Switzerland, ISBN: 978-3-030-20499-0, Washington D.C., 24-28 July 2109

I sottoscritti dichiarano che:

Laura Giraldi ha coordinate l'intero processo di stesura del paper e ha scritto le seguenti parti: Abstract, 1.1 da "The way.." a "...life," 1.2, 1.3, 2, 3.1, 3.2, 4, 5, 6

Elisabetta Benelli ha scritto: 1.1 da "Nowaday..." fino a "...dream".

Marta Mini ha scritto: 4.1 da " Interviews to educators" fino a "...needs:"

Francesca Morelli ha scritto: 4.1 da The experiment..." fino a "...playing" e References

Sottoscritto da :

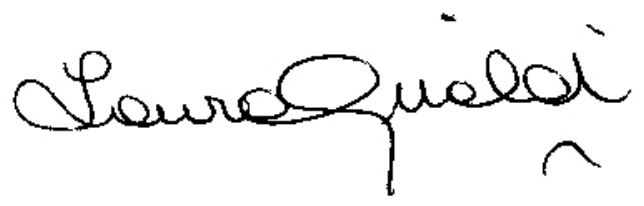

Laura Giraldi

Elisabetta Benelli

stull k

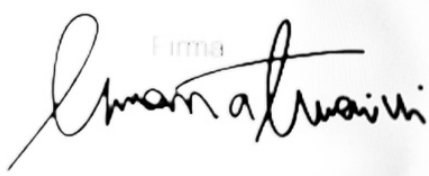

Marta Main

francesca Horelli

Francesca Morelli

Seguono i document di riconoscimento

Firenze, 10 maggio 2020 